\title{
Shortage Level of Matching Kidney and Pancreas Organs for Implant is Estimated
}

\author{
Ramalingam Shanmugam \\ School of Health Administration, Texas State University-San Marcos, TX 78666, USA
}

Received 2013-10-15, Revised 2013-10-29; Accepted 2013-11-01

\begin{abstract}
Organ transplants are increasingly done worldwide. The organ donors might be dead or alive. There are legal, ethical, medical and administrative issues to procure organs and to transplant them. However, the donor's organs must fully match the recipient's requirement before they are quickly transported as the time is the essence. The kidney or pancreas organs are more in demand. When a recipient needs two organs such as the kidney and pancreas, the requirements are made tighter and the process of finding both organs becomes tougher and longer. The patients register and wait with a hope to find both matching organs to be implanted. Because of their need for two matching organs, the patients' waiting time prolongs. In general, the number of waiting patients, $\mathrm{y}=0,1,2, \ldots$, for $\mathrm{r}=1,2, \ldots$, number of matching organs follows a negative binomial frequency pattern with $(1-p)^{\mathrm{r}}$ denoting the chance of finding $\mathrm{r}$ matching organs by any one waiting patient and $\mathrm{p}^{\mathrm{y}}$ denoting the collective chance for $\mathrm{y}$ patients not finding $\mathrm{r}$ organs. In reality, there is always a shortage of organs for waiting patients. When there is a shortage level, $0 \leq \phi<1$ of organs of the types from the living/dead donors increases, the chance for all the $\mathrm{y}$ waiting patients of not finding $\mathrm{r}$ organs should increase by a factor of $1-\phi$ and the chance for any single patient to find $r$ organs decreases accordingly. This idea triggers a need to tweak the negative binomial distribution and it is done in this article. The data for USA indicate that the kidney and pancreas implantations occur within 30 days for some patients in some states and they could take even longer than 5 years for other patients in other states. This article estimates and illustrates the importance of shortage level, $\phi$ to configure the chance of implants for patients in each state (including D.C. and Puerto Rico) of USA, with an innovative probability model. A model is necessary and it is created since the model is defined as an abstraction of the reality. The created new model in this article is named Tweaked Negative Binomial Distribution (TNBD). The properties of TNBD are derived and utilized to estimate and illustrate the shortage level, $\phi$ of kidney and pancreas organs among the Eastern (including D.C. and Puerto Rico), Central, Mountain and Pacific (including Hawaii and Alaska) states in the USA. The likelihood ratio based hypothesis testing procedure is devised, explained and demonstrated to assess the statistical significance of the estimated shortage level, $\phi$ of kidney and pancreas organs for the states in each of the four time zones in USA. The statistical power of accepting the true $50 \%$ shortage level (that is, $\phi=0.5$ ) is evaluated for the states in each of the four time zones of USA. Then, the chance of getting no transplant of kidney and pancreas organs when there is zero shortage level and the odds, of no waiting to get both kidney and pancreas transplant with the existing estimated shortage level of organs for the states in USA are explained. In the end, comments and conclusions are stated.
\end{abstract}

Keywords: Negative Binomial Distribution, Survival Probability, P-Value, Power, Test of Hypothesis, Data Analysis

\section{INTRODUCTION}

As of June 21, 2013, about 118,617 people wait for organ transplants in the United States of America (USA). Of these, 96,645 are for kidney transplants (Lumsdaine et al., 2005). The first kidney transplant in the U. S. A. was done on $17^{\text {th }}$ June 1950 in Illinois State. The pancreas needs to be implanted on diabetic patient whose organ is incapable of segregating enough insulin to continue living. Scheper-Hughes (2007) for details. The first simultaneous kidney-pancreas transplant was performed on a diabetic patient in 1966 by the University 
of Minnesota surgeons. Because of the different laws in countries, the frequency of organ donations varies among the countries. Glazier (2011) and Scheper-Hughes (2007) for laws on organ procurement and transpolantation. For example, Australia had 14.9 donors per million, Spain had 34 effective donors per millions, Austria had 21 donors/million and Germany had 16 donors/million and Greece had 6 donors/million (Tanriverdi et al., 2004). Over 100,000 Americans wait for organs and the list is growing. Only 30,000 transplants occur in a year. More than 6,000 people die in each year from lack of a donor organ, an average of 19 people a day. Tanriverdi et al. (2004) for details about the quality of life among the receipients after they received organ transplant. Over the years from 1988 till 2006, the number of transplants doubled, but the number of patients waiting for an organ grew six times. In the USA, the two agencies that govern organ procurement and distribution within the country are the United Network for Organ Sharing and the Organ Procurement and Transplant Network (DHHRUS, 2013). Both agencies implement high ethics (Truog, 2005) and standards. Not all procured organs from the donors end up implanted in recipients. The organ is scrutinized for its compatibility with the recipient's body. DHHRUS (2013) for details of organ donation and implantation. This tedious process consumes more time. The patients wait more than five years at times. In case of a need for two organs: Kidney and pancreas, the waiting time is more and the chance of getting organs depends on the matching organs. How could we estimate this unknown proportion? Such an estimate is helps the patients with a belief that they would get matching organs longer they wait. Is it so, at least in US states, according to the collected and stored data in http://optn.transplant.hrsa.gov? This query is the topic of investigation in this article.

For this purpose, an innovative tweaked version of the negative binomial distribution is introduced and utilized. The concepts and methodology are formulated. The methodological results are applied to the data on patients waiting for implantations of kidney and pancreas in US states including Puerto Rico. The findings are quite surprising in the sense that the shortage levels varied dramatically within and between the four time zones states. In specific, expressions are derived to estimate the unknown proportion of matching organs in shortage, to test the statistical significance of the estimate based on a likelihood ratio based hypothesis testing and to estimate the odds of receiving matching organs for a waiting patients across states within and between four time zones of US states including Puerto Rico. The significance of the estimate of shortage level is calculated. The statistical power of accepting true value of a shortage level by the methodology of this article is assessed. In the end, conclusive comments are made.

\subsection{Modeling Waiting Numbers for Organ Implants}

Model is an abstraction of reality (Shanmugam, 2013a; 2013b). In almost every state of USA patients in need of kidney and pancreas organs register and wait. When there are matching organs in shortage of the nation's repository, the chance of getting transplant is higher. When the transplant occurs, the patient is no longer in the waiting list. With the changing number of waiting patients, it is possible to estimate the proportion of matching organs in the shortage? This is the topics of this article. Suppose a nonnegative random number, $\mathrm{Y}=0,1,2, .$. , of patients registered and wait for a specified positive $r=1,2, .$. , number of organs to be transplanted. Let $0<p<1$ and $0 \leq \phi<1$ denote respectively the proportion getting the organs from live donors when the shortage is zero and proportion of organs in shortage match the requirements for a particular waiting patient. Let $0<\left(1-\frac{p}{1-\phi}\right)<1$ be the chance for a patient in any state or territory of USA to find the organs. An implicit meaning is that the chance to get the organs increases when $\phi$ increases. In other words, the odds of getting $r$ organs for transplant is Equation (1):

$\operatorname{Odds}_{\phi}=\left[\left(\frac{1-\phi}{1-\phi-p}\right)^{\mathrm{r}}-1\right]^{-1}$

which is maximum with zero shortage level (that is, $\phi=$ 0 ) but decreases when the shortage level, $\phi$ increases.

The importance of stocking organs for implantation cannot be overstated and it cannot happen without more donors Realize that $\phi$ is bounded by $1-p$. In this frame of uncertainty, the random number $\mathrm{Y}$ of patients waiting to receive $r$ number of organs for implantation in any state or territory of USA follows a negative binomial probability pattern Equation (2):

$$
\begin{aligned}
& \operatorname{Pr}[\mathrm{Y}=\mathrm{y} \mid \phi, \mathrm{p}, \mathrm{r}] \\
& =\left(\begin{array}{c}
\mathrm{r}+\mathrm{y}-1 \\
\mathrm{y}
\end{array}\right)\left(\frac{1-\phi-\mathrm{p}}{1-\phi}\right)^{\mathrm{r}}\left(\frac{\mathrm{p}}{1-\phi}\right)^{\mathrm{y}} \\
& \mathrm{y}=0,1,2, \ldots . ; 0 \leq \phi<1 \\
& 0<\mathrm{p}<1 ; \mathrm{r}=1,2, \ldots,
\end{aligned}
$$

The model (2) is new to the literature and it is named Tweaked Negative Binomial Distribution (TNBD). Let derive the properties of the TNBD before we can try it 
on the waiting list of patients for $r=2$ (that is, for kidney and pancreas) in USA.

First, we derive the expected value, $E[Y=y \mid \phi, p, r]$ of the TNBD and it is Equation (3):

$\mu_{\phi}=E[Y=y \mid \phi, p, r]=r\left(\frac{p}{1-\phi-p}\right)$

After simplifications the expected number, (3) of waiting patients increases when the number, $r$ of needed organs increases, when the chance, $\mathrm{p}$ of not receiving matching organs increases, or when the shortage level, $\phi$ increases.

Secondly, the variance, $\operatorname{Var}[\mathrm{Y}=\mathrm{y} \mid \phi, \mathrm{p}, \mathrm{r}]$ of the TNBD is derived and it is a quadratic function of the expected number as in (4) below Equation (4):

$$
\sigma_{\phi}^{2}=\operatorname{Var}[\mathrm{Y}=\mathrm{y} \mid \phi, \mathrm{p}, \mathrm{r}]=\frac{\mu_{\phi}\left(\mu_{\phi}+\mathrm{r}\right)}{\mathrm{r}}
$$

The results (3) and (4) together imply that the variance increases as the expected waiting number increases. That is the number of patients waiting for transplants has more volatility around the higher number of patients waiting. With $z=\sigma_{j}^{2}, y=\mu_{\phi}$ and $x=r$, the quadratic variance-mean relation (4) is depicted in Fig. 1. Note that their relationship is quite nonlinear.

Thirdly, the survival function, $\mathrm{SF}_{\phi}=\operatorname{Pr}[\mathrm{Y} \geq \mathrm{m} \mid \phi, \mathrm{p}$, $\mathrm{r}]$ of the TNBD is derived and it is Equation (5):

$$
\mathrm{SF}_{\phi}=\operatorname{Pr}\left[\mathrm{F}_{2 \mathrm{~m}, 2 \mathrm{r}} \leq \frac{\mathrm{r}(1-\phi-\mathrm{p})}{\mathrm{mp}}\right] ; \mathrm{m} \geq 1
$$

after algebraic simplifications, where $\operatorname{Pr}\left[\mathrm{F}_{2 \mathrm{~m}, 2 \mathrm{r}} \leq \mathrm{a}\right]$ is the cumulative area under the popularly tabulated Fdistribution with $2 \mathrm{~m}$ and $2 \mathrm{r}$ numerator and denominator Degrees of Freedom (DF). Realize that when $\phi \rightarrow 0$ (that is when the shortage level with matching organs is lesser), the survival function (5) becomes larger as there is more chance for patients in need of $r$ organs for transplant. Also, with a higher chance, $\mathrm{p}$ of not finding matching organs, the chance of having more waiting patients is more.

\subsection{An Estimate of Shortage Level of Matching Organs}

To check how best the collected data fit the TNBD and its properties, we need to first estimate the model parameters. For this purpose, consider a random sample $\mathrm{y}_{1}, \mathrm{y}_{2}, \ldots, \mathrm{y}_{\mathrm{n}}$ of size $\mathrm{n} \geq 2$.
Let $\bar{y}$ and $\mathrm{s}_{\mathrm{y}}^{2}$ denote respectively the sample mean and variance. The log-likelihood of the sample is Equation (6):

$$
\begin{aligned}
& \ln \mathrm{L}_{\phi}=\operatorname{nr}[\ln (1-\phi-p)-\ln (1-\phi)] \\
& -n \bar{y}[\ln \mathrm{p}-\ln (1-\phi)]+\sum_{\mathrm{i}=1}^{\mathrm{n}} \ln \left(\begin{array}{c}
\mathrm{r}+\mathrm{y}_{\mathrm{i}}-1 \\
\mathrm{y}_{\mathrm{i}}
\end{array}\right)
\end{aligned}
$$

The Maximum Likelihood Estimates (MLE) of the parameters $\phi$ and $p$ are the solutions of the score functions: $\partial_{\phi} \ln \mathrm{L}_{\phi}=0$ and $\partial_{\mathrm{p}} \ln \mathrm{L}_{\phi}=0$ where $\partial_{\mathrm{p}}$ is the partial derivative with respect to $p$. After algebraic simplifications, we obtain the MLE in (7) and (8) below. That is Equation (7):

$\hat{\phi}_{\mathrm{mle}}=\left[1-\frac{\overline{\mathrm{y}}(\overline{\mathrm{y}}+\mathrm{r})}{\mathrm{rs}_{\mathrm{y}}^{2}}\right] /\left[1+\frac{\overline{\mathrm{y}}(\overline{\mathrm{y}}+\mathrm{r})}{\mathrm{rs}_{\mathrm{y}}^{2}}\right]$

And Equation (8):

$\hat{\mathrm{p}}_{\mathrm{mle}, \hat{\phi}_{\mathrm{mle}}}=\left(\frac{\overline{\mathrm{y}}}{\overline{\mathrm{y}}+\mathrm{r}}\right)\left(1-\hat{\phi}_{\mathrm{mle}}\right)$

When $\bar{y}(\bar{y}+r)=r s_{y}^{2}$, note that $\hat{\phi}_{\text {mle }}=0$ and vice versa. Realize from (8) that $\hat{\mathrm{p}}_{\text {mle, } \hat{\phi}_{\text {mle }}}$ is its maximum $\left(\frac{\bar{y}}{\bar{y}+r}\right)$ when $\hat{\phi}_{\mathrm{mle}}=0$ and is lesser as $\hat{\phi}_{\mathrm{mle}}$ increases from zero level to one. An interpretation is that the chance, p of not getting implant is estimated to be more only when the estimated shortage level, $\hat{\phi}_{\text {mle }}$ for matching organs is zero. Otherwise, when the estimated shortage level, $\hat{\phi}_{\text {mle }}$ for matching organs increases, the estimated chance of not getting implant decreases. The importance of stocking enough matching organs cannot be overstated. To attain the enough stocking level, a promotion among the potential organ donors is a catalyst. The government and private agencies ought to undertake the promotion.

\subsection{Is the Estimate Statistically Significant?}

The likelihood ratio method (Wald, 1943) is the most powerful technique to test a null hypothesis against an alternative hypothesis. In our context, the null and alternative hypothesis are respectively $\mathrm{H}_{0}: \phi=0$ and $\mathrm{H}_{1}: \phi>0$. The likelihood ratio is Equation (9):

$$
\begin{aligned}
& -\ln \Re_{*} \\
& =-\ln \mathrm{L}\left(\phi_{*}, \hat{\mathrm{p}}_{\mathrm{mle}, \phi=\phi_{*}}\right)+\ln \mathrm{L}\left(\hat{\phi}_{\mathrm{mle}}, \hat{\mathrm{p}}_{\mathrm{mle}, \hat{\phi}_{\mathrm{mle}}}\right) \\
& =\frac{2 \mathrm{nr} \overline{\mathrm{y}}\left|\hat{\phi}_{\mathrm{mle}}-\phi_{*}\right|}{(\mathrm{r}+\overline{\mathrm{y}})}
\end{aligned}
$$




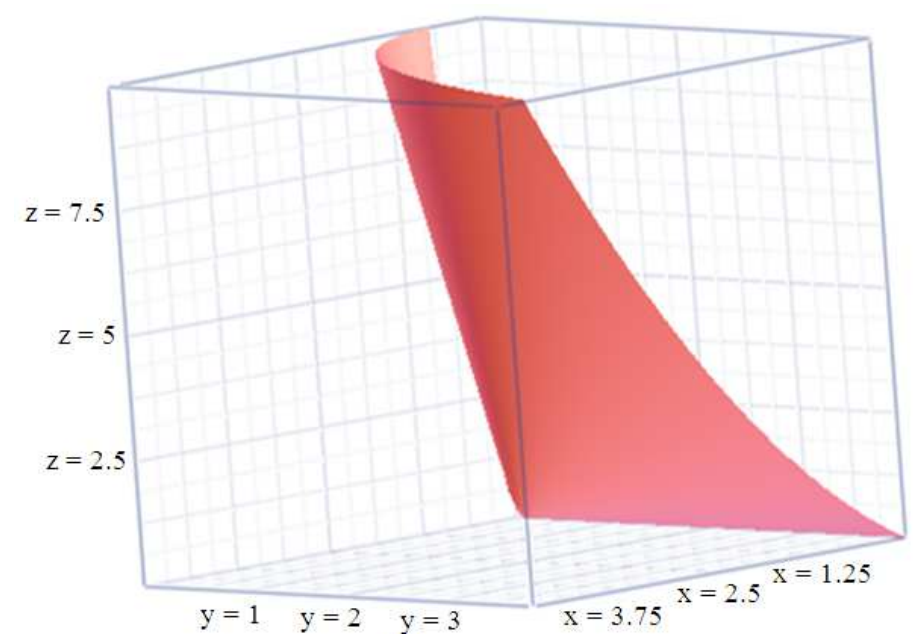

Fig. 1. Curvature relation between variance and mean

The expression (9) follows a non-central chi-squared distribution with non-centrality parameter $\delta_{*}=\left|\frac{\left(\hat{\phi}_{\mathrm{MLE}}-\phi^{*}\right)}{\operatorname{var}\left(\hat{\phi}_{\mathrm{MLE}}\right)}\right|$ where $\operatorname{var}\left(\hat{\phi}_{\mathrm{MLE}}\right)$ is a diagonal element in the variance-covariance $\operatorname{matrix} \Sigma=\left[\begin{array}{cc}\operatorname{var}\left(\hat{\phi}_{\text {mle }}\right) & \operatorname{cov}\left(\hat{\phi}_{\text {mle }}, \hat{\mathrm{p}}_{\text {mle }, \hat{\phi}_{\text {mle }}}\right) \\ \operatorname{cov}\left(\hat{\phi}_{\text {mle }}, \hat{\mathrm{p}}_{\left.\text {mle }, \hat{\phi}_{\text {mle }}\right)}\right) & \operatorname{var}\left(\hat{\mathrm{p}}_{\left.\text {mle }, \hat{\phi}_{\text {mle }}\right)}\right]\end{array}\right]=\mathrm{I}^{-1}$ which is the inverse of the Fisher's information matrix:

$$
I=E\left[\begin{array}{ll}
-\partial_{\phi \phi}^{2} \ln L & -\partial_{\phi p}^{2} \ln L \\
-\partial_{p \phi}^{2} \ln L & -\partial_{p p}^{2} \ln L
\end{array}\right]
$$

evaluated at $\left(\hat{\phi}_{\mathrm{mle}}, \hat{\pi}_{\mathrm{mle}, \hat{\phi}_{\mathrm{mle}}}\right)$. After algebraic simplifications, we note that the information matrix:

$$
\mathrm{I}=\left[\begin{array}{cc}
\frac{\mathrm{nrp}}{(1-\phi)(1-\phi-p)^{2}} & \frac{\mathrm{nr}}{(1-\phi-p)^{2}} \\
\frac{\mathrm{nr}}{(1-\phi-\mathrm{p})^{2}} & \frac{\mathrm{nr}(1-\phi)}{\mathrm{p}(1-\phi-\pi)^{2}}
\end{array}\right]
$$

is singular. The regular inverse matrix is not possible but a generalized inverse (Golub and Van Loan, 2013), $\Sigma=\mathrm{I}^{-}$ is possible. The generalized inverse has the property that $\Sigma \mathrm{I} \Sigma=\Sigma$. It is:

$$
\Sigma=\mathrm{I}^{-}=\left[\begin{array}{cc}
\frac{\mathrm{nr}(1-\phi)}{\mathrm{p}(1-\phi-\pi)^{2}} & 0 \\
0 & 0
\end{array}\right]
$$

Hence, the estimate of the non-centrality parameter is Equation (10):

$\hat{\delta}_{*}=\frac{\mathrm{rp}\left|\hat{\phi}_{\mathrm{mle}}-\phi_{*}\right|\left(1-\hat{\phi}_{\mathrm{mle}}\right)}{\mathrm{n}(\mathrm{r}+\overline{\mathrm{y}})^{2}}$

It is well known that a non-central chi-squared distribution with a non-centrality parameter $\delta$ is approximately $\left(1+\frac{\delta}{1+\delta}\right)$ times the central chi-squared distribution with $\left(\frac{[1+\delta]^{2}}{1+2 \delta}\right)$ Degrees of Freedom (DF). Hence, the null hypothesis $\mathrm{H}_{0}: \phi=0$ can be rejected in favor of the research hypothesis $\mathrm{H}_{1}: \phi>0$, when $\frac{2 n r \bar{y} \hat{\phi}_{\text {mle }}}{(\mathrm{r}+\overline{\mathrm{y}})} \quad$ exceeds its critical value $\left(1+\frac{\hat{\delta}_{0}}{1+\hat{\delta}_{0}}\right) \chi_{\left(\frac{\left[1+\hat{\delta}_{0}\right]^{2}}{1+2 \hat{\delta}_{0}}\right) \text { DF, } \alpha}^{2}$ at a chosen significance level, $\alpha$. In other words, the p-value to reject the null in favor of the research hypothesis is Equation (11):

$$
\begin{aligned}
& \mathrm{p}-\text { value } \\
& \approx \operatorname{Pr}\left[\chi_{\left(\frac{\left[1+\hat{\delta}_{0}\right]^{2}}{1+2 \hat{\delta}_{0}}\right) \text { DF }}^{2}>\frac{2 \mathrm{nr} \bar{y} \hat{\phi}_{\text {mle }}}{(\mathrm{r}+\overline{\mathrm{y}})\left(1+\frac{\hat{\delta}_{0}}{1+\hat{\delta}_{0}}\right)}\right]
\end{aligned}
$$


The (statistical) power is the probability of accepting a true specific research hypothesis $\phi^{*}=\phi_{1} \neq$ 0 . That is, for a specified significance level, $\alpha$ Equation (12):

$$
\approx \operatorname{Pr}\left[\chi_{\left(\frac{\left.1+\hat{\delta}_{*}\right]^{2}}{1+2 \hat{\delta}_{*}}\right) \text { DF }}^{\text {statistical_power }}<\frac{\left(1+\frac{\hat{\delta}_{0}}{1+\hat{\delta}_{0}}\right)\left|\left(1-\frac{\phi_{1}}{\hat{\phi}_{\mathrm{mle}}}\right)\right| \chi_{\left(\frac{\left[1+\hat{\delta}_{0}\right]^{2}}{1+2 \hat{\delta}_{0}}\right)}^{2} \mathrm{DF}, \alpha}{\left(1+\frac{\hat{\delta}_{*}}{1+\hat{\delta}_{*}}\right)}\right]
$$

\subsection{Illustration with USA Data of Kidney and Pancreas Transplant}

In this section, the expressions of the previous two sections are illustrated using the waiting list data in the U. S. Organ Procurement and Transplantation Network's webpage http://optn.transplant.hrsa.gov for kidney and pancreas organs in the Eastern (including D. C. and Puerto Rico), Central, Mountain and Pacific States of U. S. A. For each state, there are $n=8$ observations based on their waiting periods: Less than 30 days, 30 to 90 days, 90 days to 6 months, 6 months to 1 year, 1 to 2 years, 2 to 3 years, 3 to 5 years and more than 5 years.

Note that $r=2$ in the model (2) because of their need for two organs: Kidney and pancreas. Using (7) and (8), the estimates, $\hat{\phi}_{\text {mle }}$ of the proportion of matching organs in shortage and the chance, $\hat{\mathrm{p}}_{\mathrm{mle}}$ for not getting implant is done are computed. Using (11) and (12), the p-values for rejecting the null hypothesis, $\mathrm{H}_{0}: \phi=0$ and the power of accepting the true alternative hypothesis, $\mathrm{H}_{1}: \phi_{*}=0.5$ are computed for each state in the USA. The results are displayed in Table 1 through 4 respectively for the Eastern (including D. C. and Puerto Rico), Central, Mountain and Pacific States of USA.

The estimate, $\hat{\phi}_{\text {mle }}$ of the proportion of matching organs in shortage is highly significant (at $\alpha=0.01$ ) in Massachusetts, Michigan, Pennsylvania, South Carolina, Tennessee in Eastern states, Illinois, Missouri, Texas and Wisconsin in Central states and California in Pacific states of USA. The estimate, $\hat{\phi}_{\text {mle }}$ is significant (at $\alpha=$ 0.05 ) in D, C, Maryland, New Jersey, North Carolina and Virginia in Eastern states, Oklahoma in Central states and Colorado in Mountain states of U. S. A. In other states, the estimate, $\hat{\phi}_{\mathrm{mle}}$ is insignificant.

The power of accepting the true alternative hypothesis, $\mathrm{H}_{1}: \phi_{*}=0.5$ is excellent for Michigan and Tennessee in Eastern states, Illinois, Missouri and Texas in Central states of USA. The power is good in several states and low in states. There has to be some reasons for low power because of extraneous factors and it is worthwhile to explore it in another follow up article.

Furthermore, recall that $\mathrm{p}$ is the chance of not finding the matching organs. When $\phi=0$ (that is with zero shortage), it is good to have the lowest chance of not finding the organs and it occurs only in the states: Rhode Island, Nebraska, North Dakota, Hawaii and Oregon of USA.

Likewise, it is good to have the odds of not waiting for kidney and pancreas organs when $\phi \neq 0$ (that is, with a shortage of matching organs) higher than one. It occurs only in the states: Rhode Island, Kansas, Nebraska, North Dakota, Hawaii and Oregon.

\section{COMMENTS}

More populous states seem to have a higher level of shortage of organs. Intuitively, one would think that there should be more organ donors in the populous states. Shouldn't there be more organs donated by the living/dead donors in the populous states as much as equally higher amount of need for the organs? It is not seen happening. A natural question to ask is then: What are the factors that create an imbalance between the number of available and the number of needed organs? If there is more need for organs in a state, it warns an existing public health crisis in the state. If there is more shortage of available organs in the state, it reflects a lack of public awareness of the importance of donating organs in the state and it is a lack of enough promotion or administrative efficiency to procure organs from donors. The estimate of the shortage level of kidney and pancreas organs in the states (Table 1-4) of USA. is educational to us to probe the above mentioned two issues on each side of the imbalance. A lesser imbalance is witnessed in Connecticut, Kentucky, New York, Puerto Rico, Alabama, Minnesota, South Dakota, Arizona, Utah and Washington states in the USA. Such findings would not have been possible without the concepts and expressions which are derived for the TNBD in this article. 
Ramalingam Shanmugam / International Journal of Research in Nursing 4 (2): 40-46, 2013

Table 1. Estimated shortage level with $r=2$ (kidney and pancreas) organs, $p$-value, power, chance of no more waiting in Eastern US states (* $=$ significant at $0.05, * *=$ significant at 0.001 )

\begin{tabular}{|c|c|c|c|c|c|c|c|}
\hline State & $\begin{array}{l}\text { Average } \\
\text { number } \\
\text { waiting } \bar{y}\end{array}$ & $\begin{array}{l}\text { Sample } \\
\text { variance } \mathrm{s}_{\mathrm{y}}^{2}\end{array}$ & $\begin{array}{l}\text { Proportion of } \\
\text { kidney and } \\
\text { pancreas organs } \\
\text { shortage } \hat{\phi}_{\text {mle }}\end{array}$ & $\begin{array}{l}\mathrm{p} \text {-value for } \\
\mathrm{H}_{0}: \phi=0 \\
\text { to be true }\end{array}$ & $\begin{array}{l}\text { Power of } \\
\text { accepting true } \\
\mathrm{H}_{1}: \phi_{*}=0.5\end{array}$ & $\begin{array}{l}\text { Chance for no kidney } \\
\text { and pancreas } \\
\text { Transplant with no } \\
\text { shortage (that is } \phi=0 \text { ) }\end{array}$ & $\begin{array}{l}\text { Oddds }_{\hat{\phi}} \text { no waiting } \\
\text { to have kidney and } \\
\text { pancreas transplant } \\
\text { with } \hat{\phi}_{\text {mle }}\end{array}$ \\
\hline Connecticut & 1.750 & 2.79 & 0.082 & 0.27 & 0.024 & 0.429 & 0.398 \\
\hline $\mathrm{DC}$ & 2.000 & 6.86 & $0.263 *$ & 0.04 & 0.343 & 0.368 & 0.333 \\
\hline Florida & 11.630 & 48.60 & $0.240^{*}$ & 0.011 & 0.298 & 0.649 & 0.022 \\
\hline Georgia & 11.500 & 59.70 & 0.130 & 0.059 & 0.092 & 0.741 & 0.022 \\
\hline Indiana & 4.875 & 12.70 & 0.138 & 0.077 & 0.105 & 0.611 & 0.092 \\
\hline Kentucky & 2.625 & 5.70 & 0.032 & 0.447 & $1.00 \mathrm{E}-04$ & 0.55 & 0.230 \\
\hline Maryland & 4.500 & 9.71 & $0.202^{*}$ & 0.035 & 0.224 & 0.553 & 0.105 \\
\hline Massachusetts & 4.750 & 8.79 & $0.292 * *$ & 0.01 & 0.399 & 0.498 & 0.096 \\
\hline Michigan & 5.000 & 5.71 & $0.508^{* *}$ & $7.00 \mathrm{E}-04$ & 0.902 & 0.352 & 0.089 \\
\hline New Hampshire & 1.125 & 1.84 & 0.023 & 0.61 & $5.00 \mathrm{E}-06$ & 0.352 & 0.694 \\
\hline New Jersey & 6.000 & 16.60 & $0.183^{*}$ & 0.036 & 0.188 & 0.613 & 0.067 \\
\hline New York & 20.130 & 229.00 & 0.015 & 0.513 & $9.00 \mathrm{E}-09$ & 0.896 & 0.008 \\
\hline North Carolina & 8.750 & 63.40 & $0.148^{*}$ & 0.05 & 0.123 & 0.694 & 0.036 \\
\hline Ohio & 15.380 & 108.00 & 0.105 & 0.085 & 0.052 & 0.792 & 0.013 \\
\hline Pennsylvania & 16.250 & 61.90 & $0.411^{* *}$ & $6.00 \mathrm{E}-04$ & 0.641 & 0.525 & 0.012 \\
\hline Puerto Rico & 0.875 & 1.27 & 0.004 & 0.844 & $8.00 \mathrm{E}-29$ & 0.303 & 0.938 \\
\hline Rhode Island & 0.500 & 0.29 & 0.373 & 0.123 & 0.558 & 0.125 Good & 1.778 Good \\
\hline South Carolina & 6.625 & 12.00 & $0.409^{* *}$ & 0.002 & 0.637 & 0.454 & 0.057 \\
\hline Tennessee & 1.750 & 1.07 & $0.508^{* *}$ & 0.006 & 0.902 & 0.23 & 0.398 \\
\hline Vermont & 1.000 & 2.86 & 0.311 & 0.069 & 0.436 & 0.23 & 0.800 \\
\hline Virginia & 5.625 & 12.60 & $0.262 *$ & 0.013 & 0.34 & 0.545 & 0.074 \\
\hline
\end{tabular}

Table 2. Estimated shortage level with $r=2$ (kidney and pancreas) organs, $p$-value, power, chance of no more waiting in Central US states $(*=$ significant at $0.05, * *=$ significant at 0.001 )

\begin{tabular}{|c|c|c|c|c|c|c|c|}
\hline State & $\begin{array}{l}\text { Average } \\
\text { number } \\
\text { waiting } \bar{y}\end{array}$ & $\begin{array}{l}\text { Sample } \\
\text { variance } \mathrm{s}_{\mathrm{y}}^{2}\end{array}$ & $\begin{array}{l}\text { Proportion of } \\
\text { kidney and } \\
\text { pancreas organs } \\
\text { shortage } \hat{\phi}_{\text {mle }}\end{array}$ & $\begin{array}{l}\mathrm{p} \text {-value for } \\
\mathrm{H}_{0}: \phi=0 \\
\text { to be true }\end{array}$ & $\begin{array}{l}\text { Power of } \\
\text { accepting true } \\
\mathrm{H}_{1}: \phi_{*}=0.5\end{array}$ & $\begin{array}{l}\text { Chance for no kidney } \\
\text { and pancreas Transplant } \\
\text { with no shortage } \\
\text { (that is } \phi=0 \text { ) }\end{array}$ & $\begin{array}{l}\text { Odds }_{\hat{\phi}} \text { no waiting to } \\
\text { have kidney and } \\
\text { pancreas transplant } \\
\text { with } \hat{\phi}_{\text {mle }}\end{array}$ \\
\hline Alabama & 4.750 & 13.360 & 0.09 & 0.152 & 0.034 & 0.640 & 0.096 \\
\hline Illinois & 11.750 & 24.210 & $0.54 * *$ & $1 \mathrm{E}-04$ & 0.789 & 0.394 & 0.022 \\
\hline Iowa & 1.375 & 1.411 & 0.24 & 0.075 & 0.305 & 0.308 & 0.541 \\
\hline Kansas & 0.750 & 0.786 & 0.14 & 0.278 & 0.101 & 0.236 & $1.123 \mathrm{Good}$ \\
\hline Kentucky & 2.625 & 5.696 & 0.03 & 0.447 & $1 \mathrm{E}-04$ & 0.550 & 0.230 \\
\hline Louisiana & 5.500 & 14.860 & 0.16 & 0.051 & 0.15 & 0.614 & 0.077 \\
\hline Minnesota & 21.750 & 235.1 .00 & 0.05 & 0.24 & 0.002 & 0.873 & 0.007 \\
\hline Missouri & 3.625 & 2.554 & $0.60 * *$ & 4E-04 & 0.684 & 0.258 & 0.145 \\
\hline Nebraska & 0.250 & 0.500 & 0.28 & 0.319 & 0.375 & 0.080 Good & 3.765 Good \\
\hline North Dakota & 0.250 & 0.214 & 0.14 & 0.488 & 0.101 & 0.096 Good & 3.765 Good \\
\hline Oklahoma & 1.875 & 2.125 & $0.26^{*}$ & 0.044 & 0.34 & 0.357 & 0.363 \\
\hline South Dakota & 1.125 & 1.839 & 0.02 & 0.61 & $5 \mathrm{E}-06$ & 0.352 & 0.694 \\
\hline Tennessee & 1.750 & 1.071 & $0.51 * *$ & 0.006 & 0.902 & 0.230 & 0.398 \\
\hline Texas & 15.000 & 55.430 & $0.39 * *$ & 9E-04 & 0.604 & 0.535 & 0.014 \\
\hline Wisconsin & 6.125 & 3.554 & $0.75^{* *}$ & 2E-05 & 0.564 & 0.188 & 0.064 \\
\hline
\end{tabular}


Ramalingam Shanmugam / International Journal of Research in Nursing 4 (2): 40-46, 2013

Table 3. Estimated shortage level with $r=2$ (kidney and pancreas) organs, $p$-value, power, chance of no more waiting in Mountain US states $(*=$ significant at $0.05, * *=$ significant at 0.001 )

\begin{tabular}{|c|c|c|c|c|c|c|c|}
\hline State & $\begin{array}{l}\text { Average } \\
\text { number } \\
\text { waiting } \bar{y}\end{array}$ & $\begin{array}{l}\text { Sample } \\
\text { variance } \mathrm{s}_{\mathrm{y}}^{2}\end{array}$ & $\begin{array}{l}\text { Proportion of } \\
\text { kidney and } \\
\text { pancreas organs } \\
\text { shortage } \hat{\phi}_{\text {mle }}\end{array}$ & $\begin{array}{l}\mathrm{p} \text {-value for } \\
\mathrm{H}_{0}: \phi=0 \\
\text { to be true }\end{array}$ & $\begin{array}{l}\text { Power of } \\
\text { accepting true } \\
\mathrm{H}_{1}: \phi_{*}=0.5\end{array}$ & $\begin{array}{l}\text { Chance for no kidney } \\
\text { and pancreas Transplant } \\
\text { with no shortage } \\
\text { (that is, } \phi=0 \text { ) }\end{array}$ & $\begin{array}{l}\text { Odds }_{\hat{\phi}} \text { no waiting to } \\
\text { have kidney and } \\
\text { pancreas transplant } \\
\text { with } \hat{\phi}_{\text {mle }}\end{array}$ \\
\hline Arizona & 6.625 & 26.84 & 0.03 & 0.381 & 0.0001 & 0.744 & 0.057 \\
\hline Colorado & 4.375 & 20.27 & $0.18^{*}$ & 0.044 & 0.1916 & 0.559 & 0.109 \\
\hline Utah & 3.250 & 7.071 & 0.09 & 0.173 & 0.0373 & 0.561 & 0.170 \\
\hline
\end{tabular}

Table 4. Estimated shortage level with $\mathrm{r}=2$ (kidney and pancreas) organs, $\mathrm{p}$-value, power, chance of no more waiting in Pacific US states $(*=$ significant at $0.05, * *=$ significant at 0.001$)$

\begin{tabular}{|c|c|c|c|c|c|c|c|}
\hline State & $\begin{array}{l}\begin{array}{l}\text { Average } \\
\text { number }\end{array} \\
\text { waiting } \bar{y}\end{array}$ & $\begin{array}{l}\text { Sample } \\
\text { variance } \mathrm{s}_{\mathrm{y}}^{2}\end{array}$ & $\begin{array}{l}\text { Proportion of } \\
\text { kidney and } \\
\text { pancreas organs } \\
\text { shortage } \hat{\phi}_{\text {mle }}\end{array}$ & $\begin{array}{l}\mathrm{p} \text {-value for } \\
\mathrm{H}_{0}: \phi=0 \\
\text { to be true }\end{array}$ & $\begin{array}{l}\text { Power of } \\
\text { accepting true } \\
\mathrm{H}_{1}: \phi_{*}=0.5\end{array}$ & $\begin{array}{l}\text { Chance for no kidney } \\
\text { and pancreas Transplant } \\
\text { with no shortage } \\
\text { (that is, } \phi=0 \text { ) }\end{array}$ & $\begin{array}{l}\text { Odds }_{\hat{\phi}} \text { no waiting to } \\
\text { have kidney and } \\
\text { pancreas transplant } \\
\text { with } \hat{\phi}_{\text {mle }}\end{array}$ \\
\hline California & 36.37 & 339.1300 & $0.35 * *$ & 0.001 & 0.505 & 0.620 & 0.003 \\
\hline Hawaii & 0.25 & 0.2143 & 0.14 & 0.488 & 0.101 & 0.096 Good & 3.765 Good \\
\hline Oregon & 0.25 & 0.2143 & 0.14 & 0.488 & 0.101 & 0.096 Good & 3.765 Good \\
\hline Washington & 5.25 & 21.3570 & 0.06 & 0.248 & 0.006 & 0.682 & 0.082 \\
\hline
\end{tabular}

\section{CONCLUSION}

This article analyzed only the USA data. Similar patterns probably exist in other nations. With no agency in other nations collecting pertinent data of the patients waiting for transplant forbids a discussion of the situations globally. However, having sufficiently enough organs in the stock reduces the waiting time of patients. Encouraging the procurement of organs from the potential donors is an important factor. The citizens should be made aware of the importance of organ donations to save life of patients waiting for matching organs. It will be worthwhile to explore issues and their practical solutions in the procurement as well as finding matching organs for the waiting patients. This article has made a research contribution in that direction.

\section{REFERENCES}

DHHRUS, 2013. Organ procurement and transplantation network.

Glazier, A.K., 2011. Organ Donation. In: Organ Shortage: Ethics, Law and Pragmatism, Farrell, A.M., D. Price and M. Quigley (Eds.), Cambridge University Press, New York, ISBN-10: 1139500104.

Golub, G.H. and C.F. Van Loan, 2013. Matrix Computations. 1st Edn., JHU Press, Baltimore, ISBN-10: 1421407949, pp: 756.
Lumsdaine, J.A., A. Wray, M.J. Power, N.V. Jamieson and M. Akyol et al., 2005. Higher quality of life in living donor kidney transplantation: Prospective cohort study. Transplant Int., 18: 975-980. DOI: 10.1111/j.1432-2277.2005.00175.x

Scheper-Hughes, N., 2007. The tyranny of the gift: Sacrificial violence in living donor transplants. Am. J. Transplant., 7: 507-511. DOI: 10.1111/j.16006143.2006.01679.x

Shanmugam, R., 2013a. IS cancer recurrence postponed by a treatment? A new model answers. Am. Med. J., 4: 43-62. DOI: 10.3844/amjsp.2013.43.62

Shanmugam, R., 2013b. Mosaic masonries to interpret diagnostic test results. Am. Med. J., 4: 12-20. DOI: 10.3844/amjsp.2013.12.20

Tanriverdi, N., G. Ozcurumez, T. Colak, C. Duru and R. Emiroglu et al., 2004. Quality of life and mood in renal transplantation recipients, donors and controls: Preliminary report. Transplant Proc., 36: 117-119. DOI: $10.1016 /$ j.transproceed.2003.11.003

Truog, R.D., 2005. The ethics of organ donation by living donors. New Engl. J. Med., 353: 444-446. DOI: 10.1056/NEJMp058155

Wald, A., 1943. Tests of statistical hypotheses concerning several parameters when the number of observations is large. Trans. Am. Math. Soc., 54: 426-482. DOI: 10.1090/S0002-9947-19430012401-3 